\title{
Constructing a precipitable water vapor map from regional GNSS network observations without collocated meteorological data for weather forecasting
}

\author{
Biyan Chen ${ }^{1,2,3}$, Wujiao Dai ${ }^{1,2,3}$, Zhizhao Liu ${ }^{4}$, Lixin Wu ${ }^{1,3}$, Cuilin Kuang ${ }^{1,2,3}$, and Minsi Ao ${ }^{5}$ \\ ${ }^{1}$ School of Geosciences and Info-Physics, Central South University, Changsha, Hunan, China \\ ${ }^{2}$ Key Laboratory of Precise Engineering Surveying and Deformation Disaster Monitoring of Hunan Province, \\ Changsha, Hunan, China \\ ${ }^{3}$ Key Laboratory of Metallogenic Prediction of Nonferrous Metals and Geological Environment Monitoring Ministry \\ of Education, School of Geosciences and Info-Physics, Central South University, Changsha, Hunan, China \\ ${ }^{4}$ Department of Land Surveying and Geo-Informatics, Hong Kong Polytechnic University, Hong Kong, China \\ ${ }^{5}$ Hunan Province Mapping and Science and Technology Investigation Institute, Changsha, Hunan, China
}

Correspondence: Biyan Chen (yeary124@csu.edu.cn)

Received: 17 March 2018 - Discussion started: 2 May 2018

Revised: 21 August 2018 - Accepted: 22 August 2018 - Published: 11 September 2018

\begin{abstract}
Surface pressure $\left(P_{\mathrm{S}}\right)$ and weighted mean temperature $\left(T_{\mathrm{m}}\right)$ are two necessary variables for the accurate retrieval of precipitable water vapor (PWV) from Global Navigation Satellite System (GNSS) zenith total delay (ZTD) estimates. The lack of $P_{\mathrm{s}}$ or $T_{\mathrm{m}}$ information is a concern for those GNSS sites that are not collocated with meteorological sensors. This paper investigates an alternative method of inferring accurate $P_{\mathrm{s}}$ and $T_{\mathrm{m}}$ at the GNSS station using nearby synoptic observations. $P_{\mathrm{S}}$ and $T_{\mathrm{m}}$ obtained at the nearby synoptic sites are interpolated onto the location of the GNSS station by performing both vertical and horizontal adjustments, in which the parameters involved in $P_{\mathrm{s}}$ and $T_{\mathrm{m}}$ calculation are estimated from ERA-Interim reanalysis profiles. In addition, we present a method of constructing high-quality PWV maps through vertical reduction and horizontal interpolation of the retrieved GNSS PWVs. To evaluate the performances of the $P_{\mathrm{S}}$ and $T_{\mathrm{m}}$ retrieval, and the PWV map construction, GNSS data collected from 58 stations of the Hunan GNSS network and synoptic observations from 20 nearby sites in 2015 were processed to extract the PWV so as to subsequently generate the PWV maps. The retrieved $P_{\mathrm{s}}$ and $T_{\mathrm{m}}$ and constructed PWV maps were assessed by the results derived from radiosonde and the ERA-Interim reanalysis. The results show that (1) accuracies of $P_{\mathrm{s}}$ and $T_{\mathrm{m}}$ derived by synoptic interpolation are within the range of $1.7-3.0 \mathrm{hPa}$ and $2.5-3.0 \mathrm{~K}$, respectively, which are much better than the GPT2w model;
\end{abstract}

(2) the constructed PWV maps have good agreements with radiosonde and ERA-Interim reanalysis data with the overall accuracy being better than $3 \mathrm{~mm}$; and (3) PWV maps can well reveal the moisture advection, transportation and convergence during heavy rainfall.

\section{Introduction}

Water vapor is an important meteorological parameter, which plays a crucial role in the formation of various weather phenomena such as cloud, rain and snow (Ahrens and Samson, 2011). Water vapor accounts for only $0.1 \%-3 \%$ of the total atmosphere mass; however, due to the latent heat release, a small amount of water vapor may cause severe weather changes (Mohanakumar, 2008). The monitoring of atmospheric water vapor variation is thus of significant value for short-term severe weather forecasting (Brenot et al., 2013; Labbouz et al., 2013; Van Baelen et al., 2011; Zhang et al., 2015). Among the various atmosphere sensing techniques, the Global Navigation Satellite System (GNSS) is regarded as a uniquely powerful means to estimate the water vapor with advantages of all-weather capability, high accuracy and low operating expenses (Bevis et al., 1992; Guerova et al., 2016; Yao et al., 2017). 
While GNSS signals are transmitted from satellites to ground receivers, they are delayed by the terrestrial troposphere. In GNSS data processing, the tropospheric delay is usually expressed as the zenith total delay (ZTD) multiplied by a mapping function, and sometimes plus horizontal gradients for a better GNSS positioning performance ( $\mathrm{Lu}$ et al., 2016). The accuracy of the GNSS ZTD estimates depends on the data processing strategies and on the global products used in the processing. At present, ZTDs are likely to be determined with accuracies up to several millimeters by a wide range of GNSS processing software (Pacione et al., 2017; Yuan et al., 2014). ZTD is normally divided into two parts: the zenith hydrostatic delay (ZHD) which is caused by the dry gases of the troposphere and the zenith wet delay (ZWD) which stems from the water vapor. The ZHD can be accurately calculated using empirical models with surface pressure $\left(P_{\mathrm{S}}\right)$ measured by meteorological sensors (Saastamoinen, 1972). ZWD is readily obtained with the subtraction of ZHD from ZTD. The precipitable water vapor (PWV) can then be retrieved from ZWD with a conversion factor which is a function of the weighted mean temperature $\left(T_{\mathrm{m}}\right) . T_{\mathrm{m}}$ can be calculated by numerical integration from the vertical profiles of atmospheric temperature and humidity (Davis et al., 1985). PWV is a key parameter in studying water vapor variations during severe weather phenomena, since it can reflect the inflow and outflow of water vapor in a vertical air column above a certain area (Yao et al., 2017).

As stated above, the retrieval of PWV from GNSS ZTD needs two key meteorological parameters: $P_{\mathrm{S}}$ and $T_{\mathrm{m}}$. The first choice is to measure the $P_{\mathrm{s}}$ by a barometer collocated at the GNSS station. However, a large number of GNSS stations have been deployed for positioning purposes and are not equipped with collocated meteorological sensors. In this case, one may use pressure derived from a global atmospheric reanalysis (Dee et al., 2011; Zhang et al., 2017), interpolated from nearby meteorological observations (Alshawaf et al., 2015; Musa et al., 2011; Wang et al., 2007) or predicted by a blind model (Boehm et al., 2015; Wang et al., 2017). For $T_{\mathrm{m}}$, since the temperature and humidity profiles are very difficult to obtain, particularly in a near-real-time mode, $T_{\mathrm{m}}$ has to be calculated from a model. An empirical $T_{\mathrm{m}}$ model dependent on surface temperature $\left(T_{\mathrm{S}}\right)$ (Bevis et al., 1994; Li et al., 2018) or a blind model developed from atmospheric reanalysis products (Boehm et al., 2015; Yao et al., 2013; Zhang et al., 2017) is often employed.

The work presented in this paper is carried out for constructing high-quality PWV maps by a regional GNSS network in the Hunan Province, China, for precipitation forecasts and analysis. The constructed high-quality PWV maps will also be of significant value for monitoring and early warning of geological disasters, such as landslides and debris flows. In such a near-real-time application, the use of reanalysis products is not feasible. $P_{\mathrm{s}}$ and $T_{\mathrm{m}}$ have to be determined only using a blind model or nearby surface synoptic stations. The use of blind models is a very convenient means; how- ever, most blind models (e.g., global pressure and temperature 2 wet, GPT2w; Boehm et al., 2015) are developed at a global scale and are not likely to capture regional small-scale variations. More accurate $P_{\mathrm{S}}$ and $T_{\mathrm{m}}$ could be achieved by interpolation from nearby meteorological observations if they can be accessed simultaneously. In this study, we investigate the construction of PWV maps from GNSS observations over the Hunan Province by performing the following five tasks: (1) $T_{\mathrm{m}}-T_{\mathrm{s}}$ relationship and vertical reduction models for $P_{\mathrm{S}}$ and $T_{\mathrm{m}}$ are developed for each synoptic station; (2) $P_{\mathrm{s}}$ and $T_{\mathrm{m}}$ data interpolated by nearby meteorological observations are compared with those derived from radiosonde and GPT $2 w$ models; (3) a PWV vertical reduction model is developed for each GNSS station; (4) a PWV interpolation is performed over the whole Hunan region and evaluated by radiosonde and European Centre for Medium-Range Weather Forecasts (ECMWF) ERA-Interim reanalysis (hereafter abbreviated as ERA-I); and (5) the water vapor variation during a heavy rain event that occurred over a wide range of Hunan is examined based on PWV maps.

This paper is organized as follows. Section 2 presents the study area and the datasets used in the study. Section 3 describes the methodology to retrieve PWV from GNSS data. The strategy for meteorological data interpolation, $T_{\mathrm{m}}$ modeling and PWV interpolation is also presented in this section. The assessment of $P_{\mathrm{S}}$ and $T_{\mathrm{m}}$ interpolated by nearby synoptic observations is described in Sect. 4. The PWV maps constructed by GNSS data and PWV evolution during a heavy rain event are also presented in Sect. 4. The summary and conclusions are given in Sect. 5.

\section{Study area and data description}

The Hunan Province is located in the middle reaches of the Yangtze watershed in South Central China, with a territory of about $211800 \mathrm{~km}^{2}$. Hunan enjoys a subtropical humid monsoon climate bearing obvious continental climate features. The average annual rainfall varies between 1200 and $1700 \mathrm{~mm}$, with 50\%-60\% concentrating in the months from April to August. Heavy showers and thunderstorms frequently occur in summer, causing catastrophic conditions as well as significant damages to urban infrastructure and agricultural production. The monitoring of water vapor variations using the GNSS network has a great potential to improve the capacity of extreme weather forecasting in the Hunan region.

\subsection{GNSS, synoptic and radiosonde stations in Hunan}

In 2015, 58 GNSS stations were deployed in the Hunan GNSS network and new stations have subsequently been added (see Fig. 1). At present, the GNSS network consists of more than 90 stations and the number is still increasing (Li et al., 2017). Most of the GNSS stations are equipped with Trimble or Leica receivers and have a typical sampling 


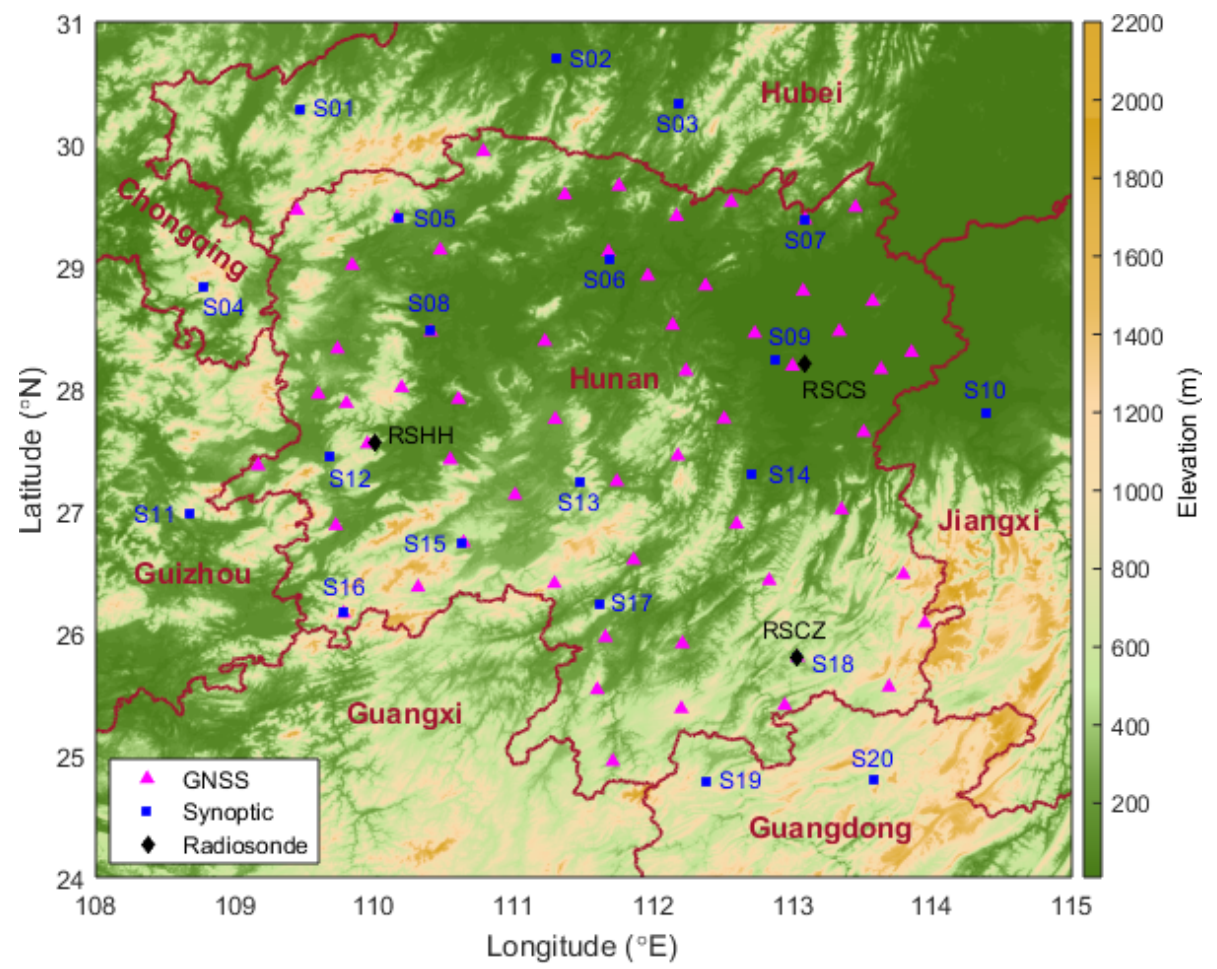

Figure 1. Geographic distribution of GNSS, synoptic and radiosonde stations in Hunan and surrounding provinces.

interval of $30 \mathrm{~s}$. In this study, the ZTDs are estimated using a GNSS precise point positioning (PPP) technique with the Bernese 5.2 software (Dach et al., 2015). To examine their performance in real-time applications, IGS (International GNSS Service) ultra-rapid satellite orbit data and clock corrections are adopted in PPP processing. The ZTDs are estimated with an interval of $30 \mathrm{~min}$, whilst the horizontal gradients are estimated every $12 \mathrm{~h}$. The global mapping function (GMF) is used (Boehm et al., 2006) in the estimation, and GNSS observations with elevation angles below $5^{\circ}$ are rejected. Evaluation results show that our estimated ZTDs have an accuracy of $\sim 9 \mathrm{~mm}$ in the comparison by radiosonde-measured ones. However, some stations in the Hunan GNSS network are not collocated with meteorological sensors; thus, they cannot be directly used for water vapor monitoring. Except the Hunan GNSS network, there are many GNSS stations without meteorological observations distributed across the province, which could be included for enhancing the quality of constructed PWV maps in the future. Therefore, a strategy of using nearby synoptic observations is needed to acquire the necessary meteorological parameters for GNSS PWV retrieval. As shown in Fig. 1, a total of 20 synoptic sites situated in Hunan and surrounding provinces can be used for this study. The average distance between a synoptic station and a GNSS station is about $41 \mathrm{~km}$. The 6-hourly pressure and temperature data measured at the synoptic sites can be retrieved from the National Center for Atmospheric Research (NCAR) (http://rda.ucar.edu/datasets/ ds336.0/, last access: March 2018). For real-time applications, pressure and temperature data at a given epoch are extrapolated from empirical models established using the past 20-day data. Here, the four-order Fourier function is adopted for the empirical models. In addition, quality-assured atmospheric profiles observed by three radiosonde sites (marked with black diamonds in Fig. 1) from the Integrated Global Radiosonde Archive (IGRA) (Durre et al., 2006) will be used to evaluate the meteorological data and PWV measurements. Both RSCS and RSCZ stations are equipped with GTS1 radiosonde sensors, whilst the type of GZZ2 sensor is adopted by the RSHH station (refer to https://www1.ncdc.noaa.gov/ pub/data/igra/history/igra2-metadata.txt, last access: March 2018).

\subsection{ECMWF reanalysis}

ECMWF ERA-Interim is a global atmospheric reanalysis from 1979, continuously updated in near-real time. In the reanalysis data generation, meteorological observations from in situ platforms (e.g., surface weather stations, ships, buoys, radiosonde stations and aircraft) and remote sensing satellites are assimilated into atmospheric physical models to recreate the past atmospheric conditions (Dee et al., 2011). Due to its high quality and global coverage, the ERA-Interim reanalysis has been exploited in various fields, e.g., GNSS meteorology (Wang et al., 2017; Zhang et al., 2017) and climate change research (Chen and Liu, 2016b; Lu et al., 2015). The ERA- 

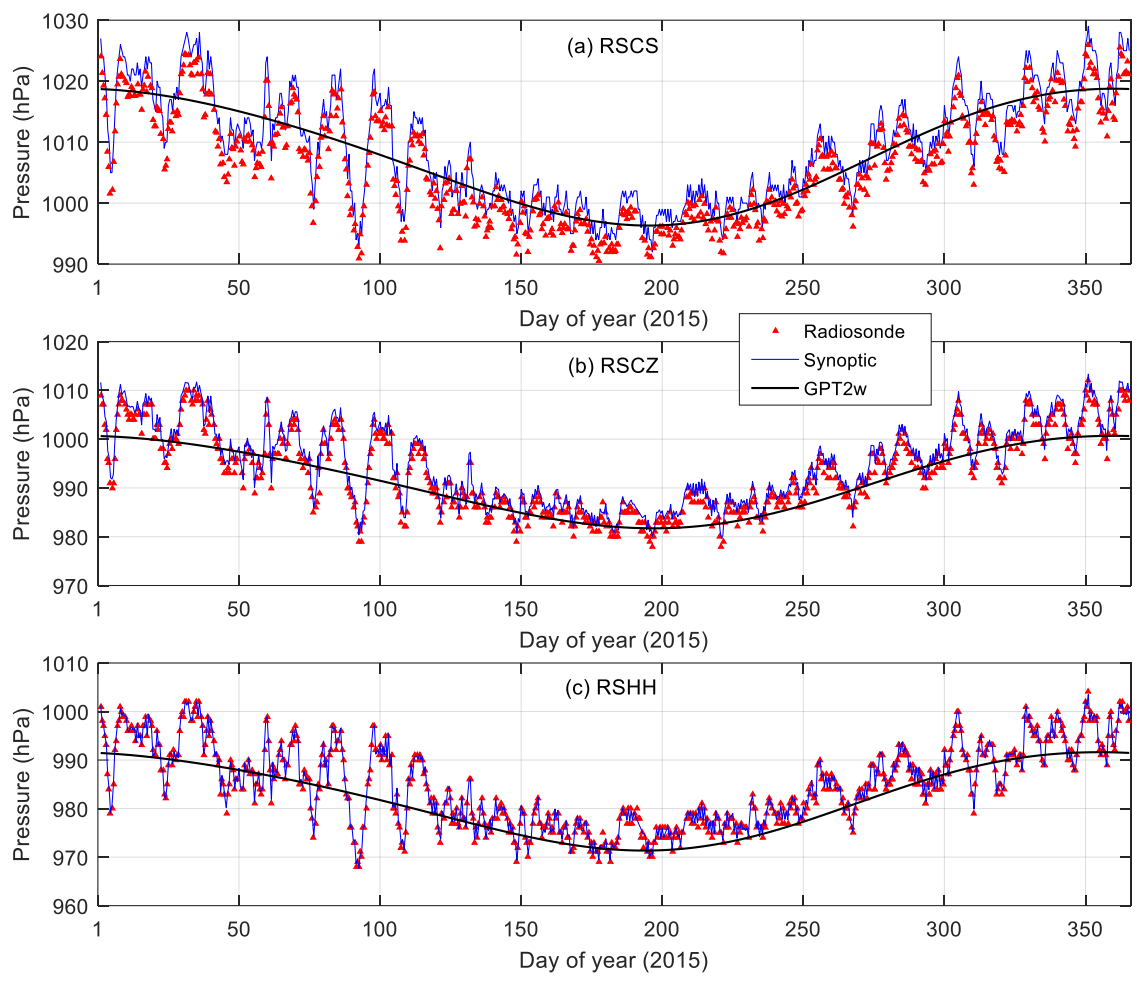

Figure 2. Time series of surface pressure provided by radiosonde, synoptic adjustment and GPT2w model over the whole year of 2015 at three radiosonde stations: (a) RSCS, (b) RSCZ and (c) RSHH, all of which are located in the Hunan Province, China.

I provides pressure, temperature, humidity and many other meteorological variables at 37 isobaric levels from 1000 to $1 \mathrm{hPa}$ with a $6 \mathrm{~h}$ interval. The reanalysis contains grid products with 11 different scales from $0.125^{\circ} \times 0.125^{\circ}$ to $3^{\circ} \times 3^{\circ}$, and the horizontal resolution of $0.25^{\circ} \times 0.25^{\circ}$ is selected for this study, which equals to about $26 \mathrm{~km}$ in Hunan.

\subsection{GPT2w model}

The global pressure and temperature (GPT) model, which is developed using spherical harmonics (Boehm et al., 2007), can provide pressure and temperature at any site in the vicinity of the Earth's surface. Lagler et al. (2013) significantly improved the GPT model, especially for its spatial and temporal variability, and named this new version as GPT2. An extension version called GPT2w was developed by Boehm et al. (2015) with improved capability to determine ZWD in blind mode. Besides the pressure and temperature, the refined GPT2w model also provides various parameters such as water vapor pressure, weighted mean temperature and the temperature lapse rate.

\section{PWV map construction with GNSS network observations}

\subsection{Retrieval of PWV from GNSS ZTD}

To retrieve PWV from GNSS-inferred ZTD, ZHD should be determined first. The ZHD calculation formula is theoretically derived based on the assumption that the air is an ideal gas and that the troposphere satisfies the hydrostatic equilibrium (Davis et al., 1985). Saastamoinen (1972) derived the most widely used ZHD model as follows (Chen and Liu, 2016a):

$\mathrm{ZHD}=2.2793 P_{\mathrm{s}} /(1-0.0026 \cos 2 \varphi-0.00028 h)$

where $\varphi$ is the station latitude (unit: radians) and $h$ is the height of the station above sea level (unit: $\mathrm{km}$ ). By subtracting ZHD from ZTD, the remainder ZWD can then be converted to PWV by using the formula below (Askne and Nordius, 1987):

$\mathrm{PWV}=\frac{10^{5}}{\left(k_{3} / T_{\mathrm{m}}+k_{2}^{\prime}\right) R_{v}} \mathrm{ZWD}$,

where $k_{3}=3.776 \times 10^{5} \mathrm{~K}^{2} \mathrm{hPa}^{-1}, k_{2}^{\prime}=16.52 \mathrm{~K} \mathrm{hPa}^{-1}$ and $R_{v}=461.495 \mathrm{~J} \mathrm{Kkg}^{-1}$ are physical constants (Rüeger, 2002). The weighted mean temperature $T_{\mathrm{m}}$ is defined as fol- 
lows (Davis et al., 1985):

$T_{\mathrm{m}}=\frac{\int \frac{e(h)}{T(h)} \mathrm{d} h}{\int \frac{e(h)}{T(h)^{2}} \mathrm{~d} h}$,

where $e(h)$ and $T(h)$ are the water vapor pressure (hPa) and temperature (K) at height $h$, respectively. Since the humidity and temperature profiles are usually unavailable, a linear relationship between surface temperature $T_{\mathrm{s}}$ and $T_{\mathrm{m}}$ is often adopted to determine the $T_{\mathrm{m}}$ :

$T_{\mathrm{m}}=a+b T_{\mathrm{s}}$,

where $a$ and $b$ are coefficients that need to be fitted locally using radiosonde or reanalysis profiles.

\subsection{Spatial adjustments for $\boldsymbol{P}_{\mathrm{s}}$ and $\boldsymbol{T}_{\mathrm{m}}$}

Because some stations in the Hunan GNSS network are not equipped with meteorological sensors, a method of spatially adjusting nearby meteorological observations to the GNSS stations was developed. Adjacent synoptic sites within the $100 \mathrm{~km}$ radius of a given GNSS station are employed in the adjustments. The adopted radius ensures at least one synoptic site being located within the circumference centered on the GNSS station. For each GNSS site, on average, two synoptic stations fall into that circumference. First, surface pressure and mean weighted temperature data at the synoptic sites are adjusted to the height $H_{\mathrm{s}}$ of the given GNSS station (Zhang et al., 2017):

$P_{\mathrm{s}}=P_{\mathrm{r}} e^{\mu\left(H_{\mathrm{s}}-H_{\mathrm{r}}\right)}$,

$T_{\mathrm{m}}=T_{\mathrm{mr}}+\alpha\left(H_{\mathrm{s}}-H_{\mathrm{r}}\right)$,

where $P_{\mathrm{r}}, T_{\mathrm{mr}}$ and $H_{\mathrm{r}}$ are the pressure $(\mathrm{hPa})$, weighted mean temperature $(\mathrm{K})$ and height $(\mathrm{km})$ at the synoptic site, respectively. Here, $T_{\mathrm{mr}}$ is calculated by Eq. (4) using the surface temperature $(\mathrm{K})$ measured on site. $P_{\mathrm{s}}$ and $T_{\mathrm{m}}$ are the pressure and weighted mean temperature corresponding to the height $H_{\mathrm{s}}$ at the synoptic site. $\mu$ and $\alpha$ are parameters needed to be estimated at the synoptic site.

Then the vertically adjusted meteorological data are interpolated to the location of the GNSS station according to

$\mathrm{y}_{\mathrm{G}}=\frac{\sum_{i=1}^{n} \exp \left(-d_{i}^{2}\right) \times y_{i}}{\sum_{i=1}^{n} \exp \left(-d_{i}^{2}\right)}$,

where $n$ is the number of synoptic sites with a distance less than $100 \mathrm{~km}$ to the given GNSS site, $\mathrm{y}_{\mathrm{G}}$ is the interpolated value, $y_{i}$ is the adjusted meteorological data at synoptic site $i$, and $d_{i}$ is the distance between synoptic site $i$ and the GNSS station.
Table 1. Estimated values of $a, b, \mu$ and $\alpha$ for the 20 synoptic sites using ERA-I atmospheric profiles over the whole year of 2014.

\begin{tabular}{lrrrr}
\hline Station & \multicolumn{4}{c}{ Parameters } \\
\cline { 2 - 5 } & $a$ & $b$ & $\mu$ & $\alpha$ \\
\hline S01 & 264.72 & 0.82 & -0.1110 & -4.47 \\
S02 & 264.40 & 0.83 & -0.1112 & -4.48 \\
S03 & 264.90 & 0.82 & -0.1106 & -4.25 \\
S04 & 267.08 & 0.75 & -0.1102 & -3.76 \\
S05 & 265.67 & 0.79 & -0.1111 & -4.05 \\
S06 & 266.46 & 0.78 & -0.1104 & -3.90 \\
S07 & 265.68 & 0.79 & -0.1103 & -4.16 \\
S08 & 266.49 & 0.77 & -0.1108 & -3.79 \\
S09 & 267.32 & 0.73 & -0.1101 & -3.88 \\
S10 & 267.23 & 0.73 & -0.1102 & -4.09 \\
S11 & 269.07 & 0.67 & -0.1097 & -3.66 \\
S12 & 267.99 & 0.72 & -0.1105 & -3.66 \\
S13 & 268.40 & 0.70 & -0.1105 & -3.64 \\
S14 & 268.74 & 0.65 & -0.1074 & -4.06 \\
S15 & 269.02 & 0.68 & -0.1103 & -3.69 \\
S16 & 269.56 & 0.66 & -0.1099 & -3.78 \\
S17 & 269.43 & 0.66 & -0.1102 & -3.70 \\
S18 & 269.52 & 0.65 & -0.1099 & -3.96 \\
S19 & 270.27 & 0.63 & -0.1096 & -4.04 \\
S20 & 269.82 & 0.64 & -0.1094 & -4.14 \\
\hline
\end{tabular}

\subsection{PWV interpolation from GNSS stations}

With the use of interpolated $P_{\mathrm{s}}$ and $T_{\mathrm{m}}$, PWV data at the GNSS stations could be obtained in near-real time. In order to construct the PWV map, GNSS PWV data are used to interpolate at a $0.25^{\circ} \times 0.25^{\circ}$ grid. Similar to the meteorological data, PWVs at nearby GNSS stations are interpolated to the given height $H_{\mathrm{p}}$ of the grid point as follows (Dousa and Elias, 2014):

$\mathrm{PWV}=\mathrm{PWV}_{\mathrm{r}}\left[1-\frac{\beta\left(H_{\mathrm{s}}-H_{\mathrm{r}}\right)}{T_{\mathrm{s}}}\right]^{\frac{\theta \times g}{\beta \times R_{\mathrm{d}}}}$,

where $\mathrm{PWV}_{\mathrm{r}}$ is the PWV estimated at the GNSS station, $\beta$ refers to the temperature lapse rate (unit: $\mathrm{K} \mathrm{km}^{-1}$ ), $\theta$ is a numerical coefficient, $g$ is gravity acceleration (unit: $\mathrm{m} \mathrm{s}^{-2}$ ), and $R_{\mathrm{d}}=287.053 \mathrm{~J} \mathrm{~K}^{-1} \mathrm{~kg}^{-1}$ is the gas constant for dry air. Both $\beta$ and $\theta$ are required to be determined from local observations for a better performance. The PWV at the grid point can then be acquired by interpolation using Eq. (7). In this study, the height of each grid point is derived from the global topography-bathymetry grid that has a 30 arcsec resolution (SRTM30 PLUS) (Becker et al., 2009). 


\section{Results and discussion}

\subsection{Evaluation of $\boldsymbol{P}_{\mathrm{S}}$ and $\boldsymbol{T}_{\mathrm{m}}$ interpolated by synoptic data}

All the parameters including $a$ and $b$ in Eq. (4), $\mu$ in Eq. (5) and $\alpha$ in Eq. (6) are estimated locally at each synoptic site using reanalysis products. In this study, the values of $a, b$, $\mu$ and $\alpha$ (their values are given in Table 1) for each site are fitted from ERA-I atmospheric profiles over the whole year of 2014. With the use of the estimated parameters, spatial adjustments for $P_{\mathrm{s}}$ and $T_{\mathrm{m}}$ to radiosonde stations are performed throughout the year of 2015 . Then the interpolated meteorological data are directly compared with the radiosonde observations.

Figure 2 shows the time series of $P_{\mathrm{s}}$ provided by radiosonde, synoptic interpolation and the GPT2w model at three radiosonde stations over 2015. Surface pressures interpolated from synoptic observations have a very good agreement with radiosonde-measured ones. The GPT $2 \mathrm{w}$ model basically reflects the variation trend of $P_{\mathrm{s}}$ throughout the year; however, it is unable to capture the fluctuations which are especially obvious in winter and spring months. Similar results can be observed in Fig. 3 for $T_{\mathrm{m}}$ comparison. Detailed statistics of the comparison results are given in Table 2. The root-mean-square errors (RMSEs) of $P_{\mathrm{s}}$ and $T_{\mathrm{m}}$ derived from synoptic interpolation vary in the range of $1.7-3.0 \mathrm{hPa}$ and 2.5-3.0 K, respectively. In comparison, the RMSEs from the GPT2w model are 4.7-5.6 hPa and 3.8-4.2 K, respectively, for $P_{\mathrm{s}}$ and $T_{\mathrm{m}}$, which are much larger than the synoptic interpolation method. In terms of maximum and minimum differences, GPT2w-derived values are significantly larger than those derived from synoptic interpolation, further indicating the GPT2w model is less accurate. According to Eq. (1), a $1 \mathrm{hPa}$ error in surface pressure would cause about a $2.3 \mathrm{~mm}$ error in ZHD. Therefore, a $3 \mathrm{hPa}$ error in $P_{\mathrm{s}}$ will result in an error of about $6.9 \mathrm{~mm}$ in ZHD $(\sim 1.15 \mathrm{~mm}$ in PWV). The relative error of the PWV caused by the $T_{\mathrm{m}}$ error is approximately equal to the relative error of the $T_{\mathrm{m}}$ (Zhang et al., 2017). Derived from Fig. 3 and Table 2, the relative error of synoptic-data-interpolated $T_{\mathrm{m}}$ is about $1 \%$. In the study region, the PWV value is usually less than $80 \mathrm{~mm}$, meaning the PWV error caused by the $T_{\mathrm{m}}$ error is within $0.8 \mathrm{~mm}$. In addition, as mentioned in Sect. 2.1, our estimated ZTDs have an accuracy of about $9 \mathrm{~mm}(\sim 1.45 \mathrm{~mm}$ in PWV). On the whole, the accuracy of PWV retrieved from GNSS ZTD using $P_{\mathrm{s}}$ and $T_{\mathrm{m}}$ from synoptic interpolation is better than $3.4 \mathrm{~mm}$. Following the same error analysis, the uncertainty of PWV caused by the GPT2w model is about $4.6 \mathrm{~mm}$.

\subsection{Evaluation of PWV by radiosonde}

At each GNSS station, GNSS-derived ZTDs are converted to PWVs with the use of meteorological parameters interpolated from synoptic data. In order to evaluate the GNSS- derived PWV, the GNSS PWVs are interpolated onto the radiosonde stations according to Eqs. (7) and (8) for a direct comparison with radiosonde-measured ones. As displayed in Fig. 4, GNSS-interpolated PWVs agree well with the radiosonde-measured ones at all the three radiosonde stations. Mean biases of the PWV differences at RSCS, RSCZ and RSHH station are $-0.59,1.04$ and $1.40 \mathrm{~mm}$, respectively (see Table 3). In terms of the RMSE, they are 2.47, 2.94 and $2.69 \mathrm{~mm}$ for RSCS, RSCZ and RSHH stations, respectively. It is notable that for weather nowcasting, the accuracy threshold is $3 \mathrm{~mm}$ (Yuan et al., 2014). This indicates that the GNSS-derived PWVs are accurate enough for the application of weather nowcasting. Additionally, the probability density function (PDF) of PWV differences and the fractional error as percent by radiosonde $5 \mathrm{~mm}$ PWV bins are exhibited in Fig. 5. As shown in Fig. 5a, about $83 \%$ PWV differences are within the range of -5 to $5 \mathrm{~mm}$. The fractional errors vary from about $-15 \%$ to $6 \%$ as radiosonde PWV increases from 0 to $75 \mathrm{~mm}$. When PWV values are less than $10 \mathrm{~mm}$, there is an obvious wet bias relative to the radiosonde. This is probably related to the dry bias of Chinese-made GTS1 and GZZ2 radiosonde sensors caused by solar heating (Moradi et al., 2013), whereas an obvious dry bias can be observed for PWV values larger than $65 \mathrm{~mm}$. The dry bias is likely due to the overestimation of water vapor by radiosonde as the Chinese radiosonde types are known to have a moist bias for large PWV ranges (Nash et al., 2011). A similar effect has also been found for other radiosonde types and was ascribed to the humidity sensors suffering from contamination from rain and clouds during radiosonde ascents (Bock et al., 2005).

\subsection{PWV comparison between ERA-I products and GNSS interpolation data}

The ERA-I products are used to further assess the performance of PWV maps constructed by the GNSS network data. For the comparison, the GNSS PWVs are interpolated onto grid points with a spatial resolution of $0.25^{\circ}$ in both latitude and longitude directions to match the ERA-I PWV data. Figure 6 presents the spatial distribution of the bias and RMSE of the PWV differences between ERA-I and GNSS over the Hunan region. As seen in Fig. 6a, the bias varies from -8 to $6 \mathrm{~mm}$ depending upon the location. In general, mountainous regions have a larger bias than plain regions. In terms of RMSE, as shown in Fig. 6b, its values vary in the range of 2-8 $\mathrm{mm}$. Large parts of the studied region are populated with RMSEs less than $3 \mathrm{~mm}$. However, relatively large RMSEs of more than $6 \mathrm{~mm}$ are obtained for some mountainous regions.

In addition, the PDF of the PWV differences shown in Fig. 7a indicates that there is a higher probability of negative PWV difference. Negative values account for about $64 \%$ of the total PWV difference. The fractional error as percent by ERA-I $5 \mathrm{~mm}$ PWV bins varies greatly from about $-65 \%$ to $10 \%$. When PWV values are smaller than $10 \mathrm{~mm}$, there is an 

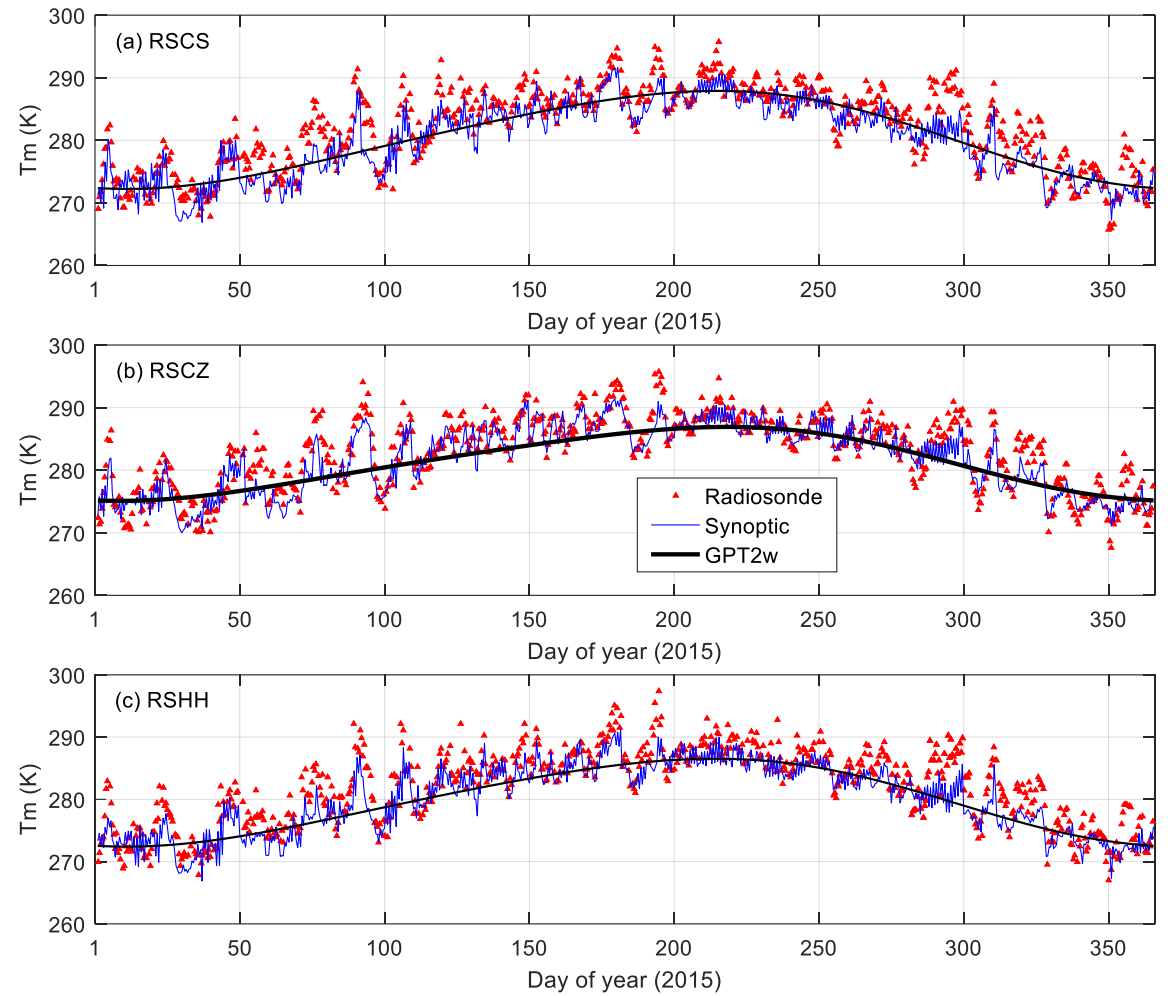

Figure 3. Time series of weighted mean temperature provided by radiosonde, synoptic adjustment and GPT2w model over the whole year of 2015 at three radiosonde stations: (a) RSCS, (b) RSCZ and (c) RSHH, all of which are located in the Hunan Province, China.

Table 2. Comparison of $P_{\mathrm{S}}$ and $T_{\mathrm{m}}$ for radiosonde-synoptic and radiosonde-GPT2 $\mathrm{w}$ at the three radiosonde stations.

\begin{tabular}{llrr|rr|rr}
\hline \multirow{2}{*}{ Comparison } & & \multicolumn{2}{c}{ RSCS } & \multicolumn{2}{c|}{ RSCZ } & \multicolumn{2}{c}{ RSHH } \\
\cline { 3 - 7 } & & $P_{\mathrm{S}}(\mathrm{hPa})$ & $T_{\mathrm{m}}(\mathrm{K})$ & $P_{\mathrm{S}}(\mathrm{hPa})$ & $T_{\mathrm{m}}(\mathrm{K})$ & $P_{\mathrm{S}}(\mathrm{hPa})$ & $T_{\mathrm{m}}(\mathrm{K})$ \\
\hline Radiosonde vs. synoptic & Bias & 2.91 & 1.47 & -1.66 & 1.14 & -2.58 & 1.49 \\
& RMSE & 2.97 & 2.92 & 1.74 & 2.58 & 2.61 & 2.76 \\
& Max & 5.04 & 9.69 & 0.48 & 7.42 & -1.33 & 9.17 \\
& Min & 1.01 & -6.40 & -3.82 & -5.18 & -3.82 & -5.40 \\
\hline Radiosonde vs. GPT2w & Bias & 1.23 & 1.59 & 2.02 & 1.68 & 3.06 & 2.23 \\
& RMSE & 4.70 & 3.84 & 4.76 & 4.02 & 5.56 & 4.16 \\
& Max & 13.75 & 13.29 & 12.26 & 14.21 & 14.96 & 14.48 \\
& Min & -16.13 & -7.44 & -13.46 & -8.08 & -14.94 & -6.34 \\
\hline
\end{tabular}

Table 3. Comparison between radiosonde-observed and GNSSinterpolated PWV at the three radiosonde stations.

\begin{tabular}{lrrrr}
\hline $\begin{array}{l}\text { Radiosonde } \\
\text { station }\end{array}$ & $\begin{array}{r}\text { Bias } \\
(\mathrm{mm})\end{array}$ & $\begin{array}{r}\text { RMSE } \\
(\mathrm{mm})\end{array}$ & $\begin{array}{r}\text { Max } \\
(\mathrm{mm})\end{array}$ & $\begin{array}{r}\text { Min } \\
(\mathrm{mm})\end{array}$ \\
\hline RSCS & -0.59 & 2.47 & 7.46 & -7.96 \\
RSCZ & 1.04 & 2.94 & 10.44 & -11.15 \\
RSHH & 1.40 & 2.69 & 9.27 & -8.59 \\
\hline
\end{tabular}

obvious wet bias relative to the ERA-I. The largest negative fractional error occurs at the extremely low (less than $5 \mathrm{~mm}$ ) PWV values. When PWV values are larger than $60 \mathrm{~mm}$, dry bias relative to ERA-I can be observed for PWV values. Figure $7 c$ exhibits the relationship between RMSE and elevation. It is clearly seen that the RMSE increases generally with increase in elevation. A high correlation coefficient of 0.73 is achieved between RMSE and elevation. This is consistent with the bias and RMSE maps in Fig. 6. The high correlation coefficient is probably due to the following reasons: (1) vertical adjustment for PWV according to Eq. (8) is unable to 

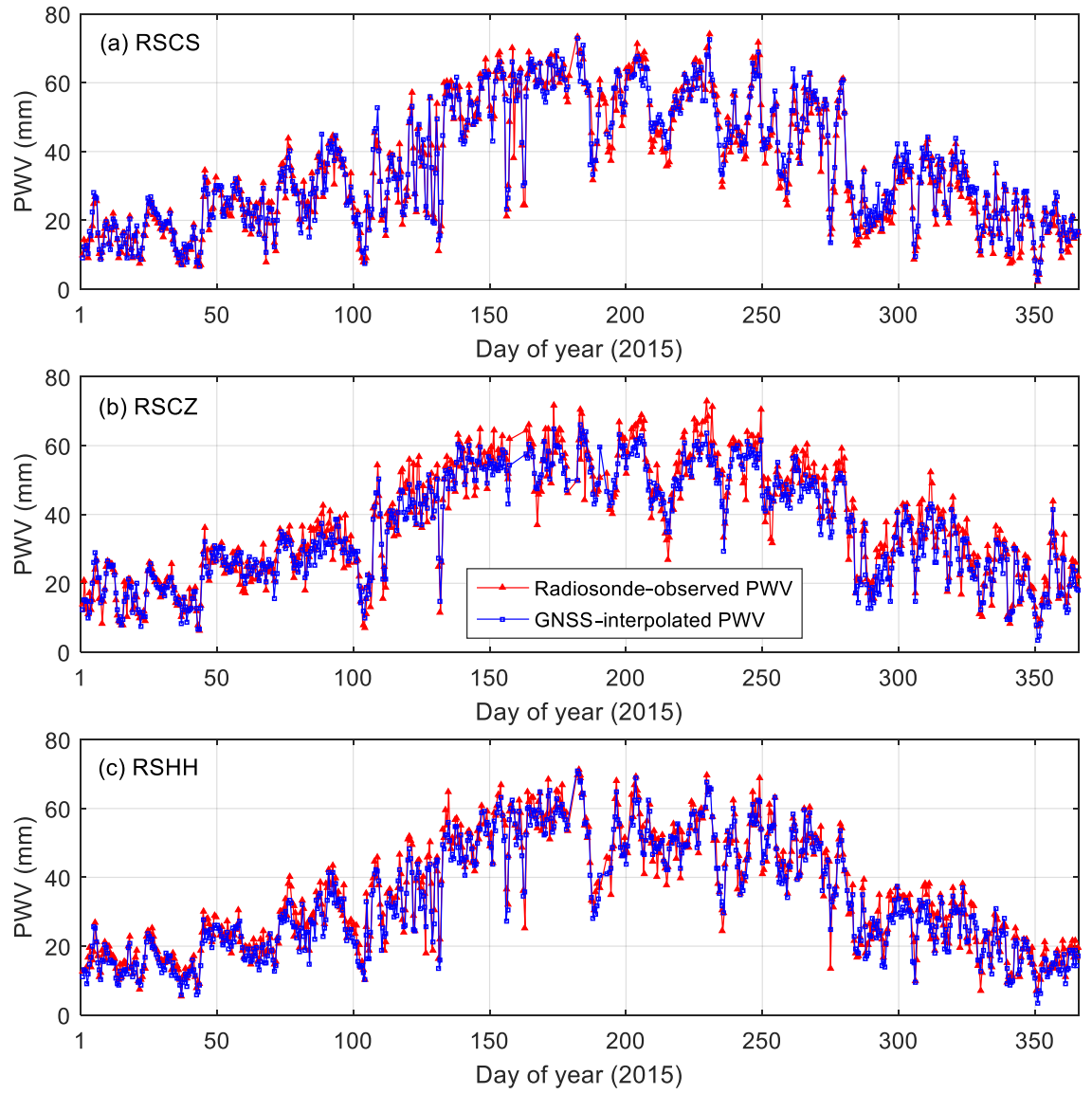

Figure 4. Time series of PWV measured by radiosonde and interpolated by GNSS over the whole year of 2015 at three radiosonde stations: (a) RSCS, (b) RSCZ and (c) RSHH.
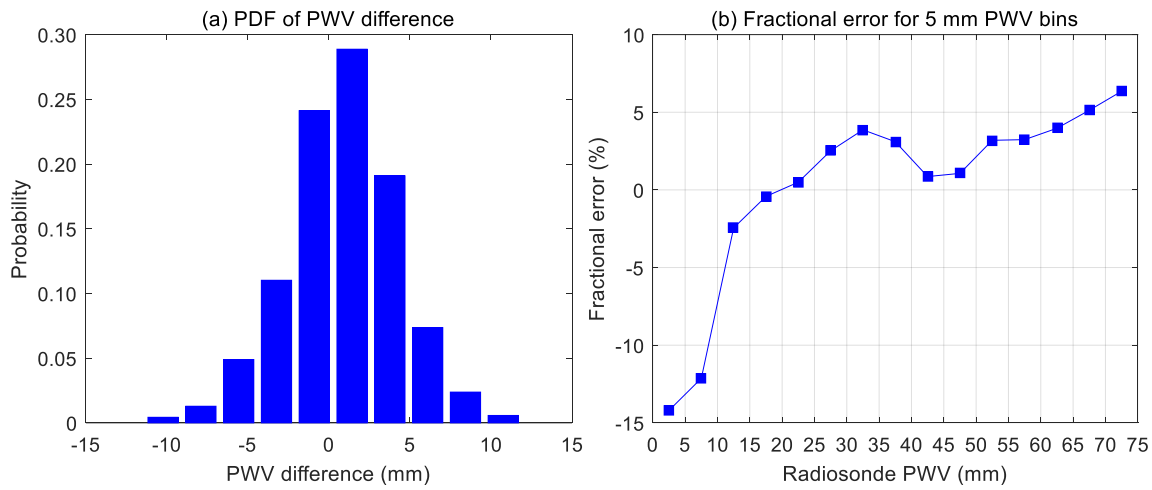

Figure 5. (a) PDF of PWV difference and (b) fractional error as percent by radiosonde $5 \mathrm{~mm}$ PWV bins. All the three radiosonde stations are used in the statistics. 

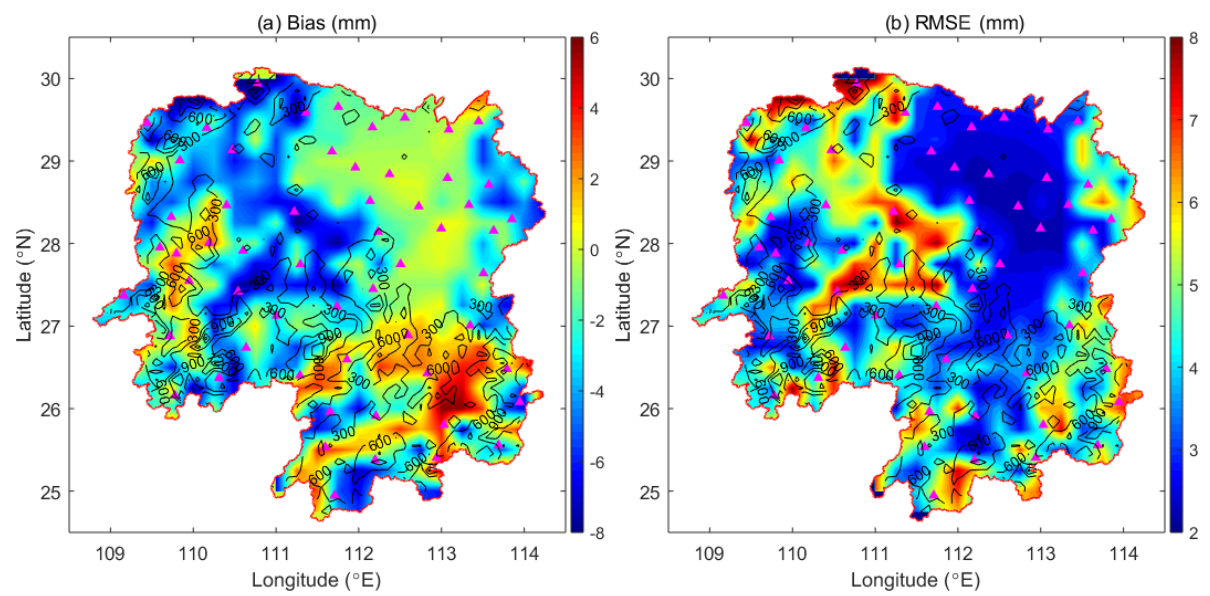

Figure 6. Map of (a) bias and (b) RMSE of the differences between ERA-I PWV and GNSS-interpolated PWV over the Hunan Province for the year 2015. Black contours represent the elevation (unit: $\mathrm{m}$ ).
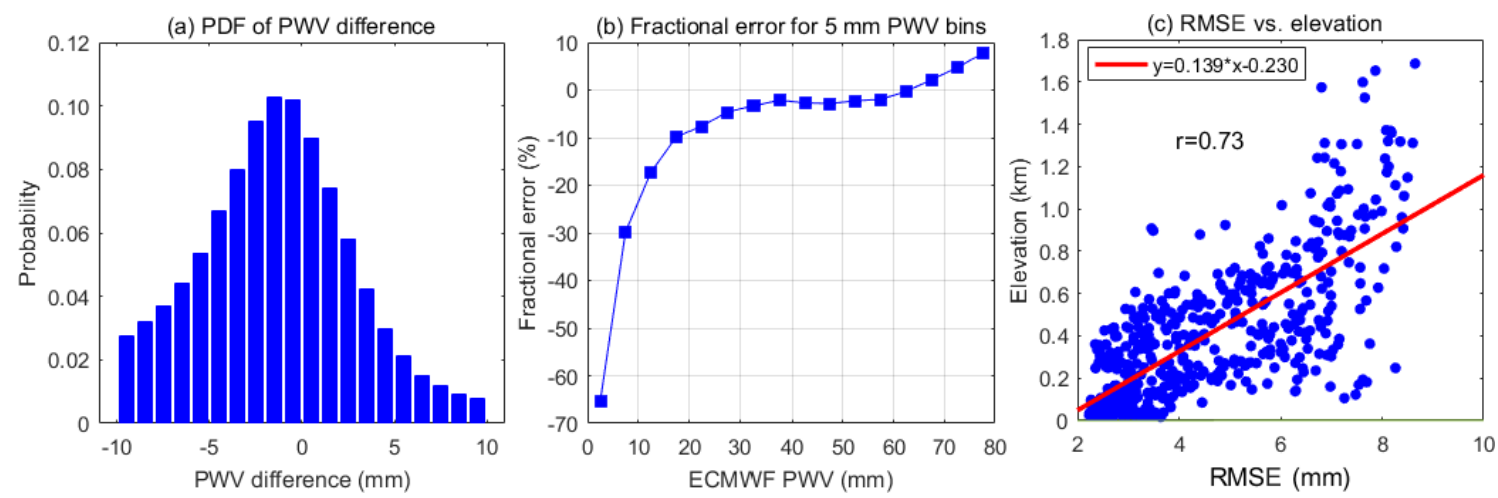

Figure 7. (a) PDF of PWV difference, (b) fractional error as percent by ERA-I $5 \mathrm{~mm}$ PWV bins, and (c) relationship between RMSE and elevation for the comparison between ERA-I and GNSS.

accurately capture the highly dynamic water vapor variation in the vertical direction and (2) the performance of the ERAI PWV product degrades in mountainous regions due to the larger errors caused by PWV averaging over cells with highly variable surface topography (Alshawaf et al., 2017).

\subsection{Monitoring water vapor variations using GNSS-derived PWV maps}

The ultimate goal of this study is to apply the constructed PWV maps for the study of weather forecasting. We further investigated the water vapor variations during a largescale heavy-precipitation event using the PWV maps derived from GNSS observations. In June 2015, the Hunan Province suffered several large-scale regional torrential rains, which caused major floods and massive landslides in some places. An average rainfall of $236 \mathrm{~mm}$ over the whole province was recorded in that month, and the accumulated rainfall exceeded $500 \mathrm{~mm}$ in many areas. In this study, we focused on a heavy rainfall process occurring during 6-8 June 2015. Figure 8 exhibits the geographic distribution of the daily accu- mulated precipitation over the Hunan Province for 6, 7 and 8 June 2015. The precipitation data are retrieved from the Tropical Rainfall Measuring Mission (TRMM), a joint mission of NASA (National Aeronautics and Space Administration) and the Japan Aerospace Exploration Agency to measure rainfall for weather and climate research (Kummerow et al., 1998; Lau and Wu, 2011). As shown in Fig. 8a, the accumulated precipitation on 6 June decreased from about $60 \mathrm{~mm}$ at the southeast to $0 \mathrm{~mm}$ at the northwest. On 7 June, rainfalls were observed over most parts of the province with heavy precipitation mainly occurring in the northern Hunan Province. Afterwards, on 8 June, the precipitation weakened on most of the Hunan Province except for an increase in the northeast.

Figure 9 presents the evolution of PWV derived from GNSS observations for the Hunan Province during the period of 6-8 June 2015 with a time interval of $6 \mathrm{~h}$. In addition, the TRMM-derived rain rates over Hunan for the same epochs are displayed in Fig. 10. On 6 June (see Fig. 9ad), the whole province experienced an obvious increase in 

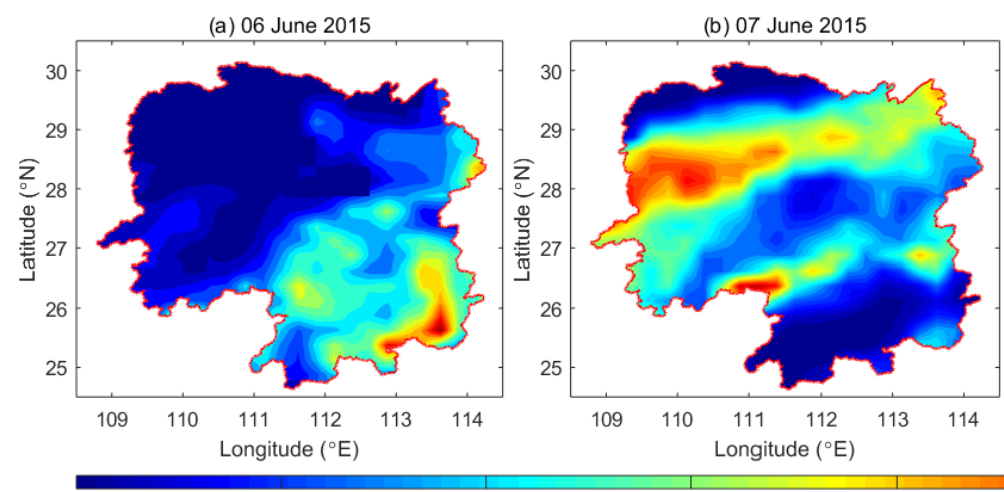

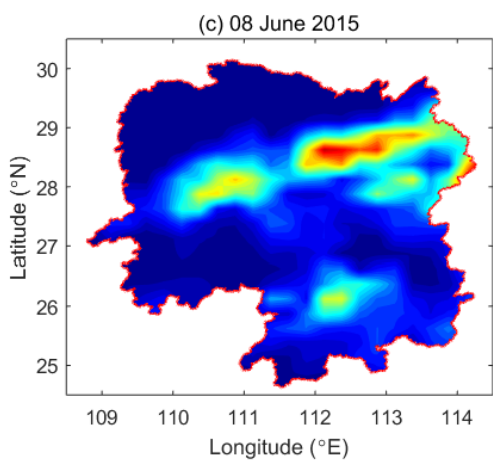

60

Figure 8. Map of daily accumulated precipitation in the Hunan Province on (a) 6 June 2015, (b) 7 June 2015 and (c) 8 June 2015 . The precipitation data were retrieved from the TRMM with a spatial resolution of $0.25^{\circ} \times 0.25^{\circ}$.

(a) $06 / 06 / 2015$ 00:00 UTC

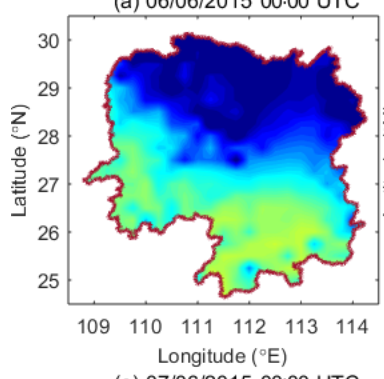

(e) 07/06/2015 00:00 UTC

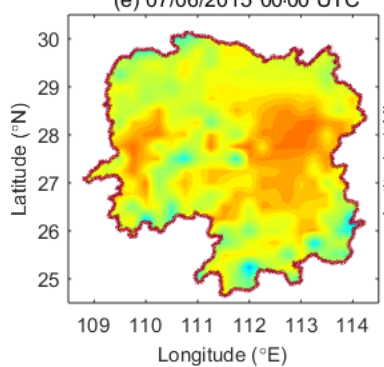

(i) 08/06/2015 00:00 UTC

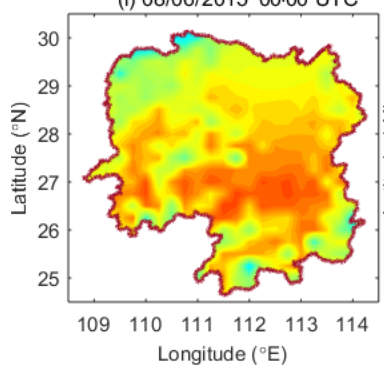

(b) 06/06/2015 06:00 UTC

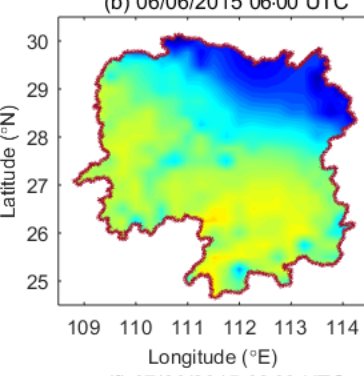

(f) $07 / 06 / 2015$ 06:00 UTC

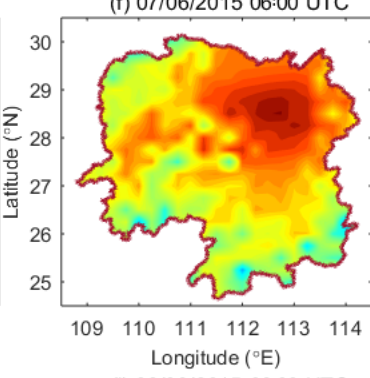

(j) 08/06/2015 06:00 UTC

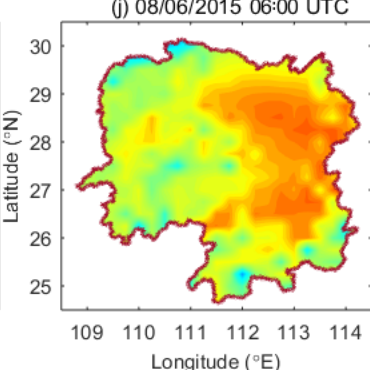

(c) $06 / 06 / 201512: 00$ UTC

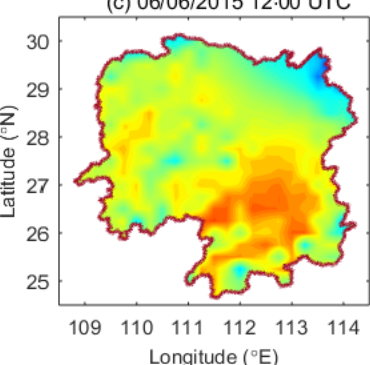

(g) $07 / 06 / 2015$ 12:00 UTC

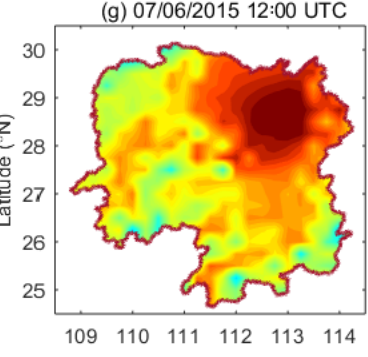

Longitude $\left({ }^{\circ} \mathrm{E}\right)$

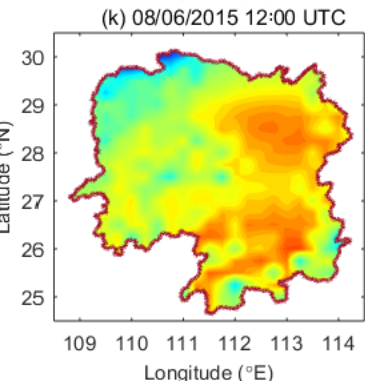

(d) 06/06/2015 18:00 UTC

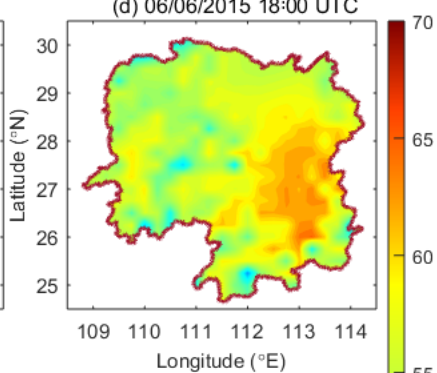

(h) $07 / 06 / 201518: 00$ UTC

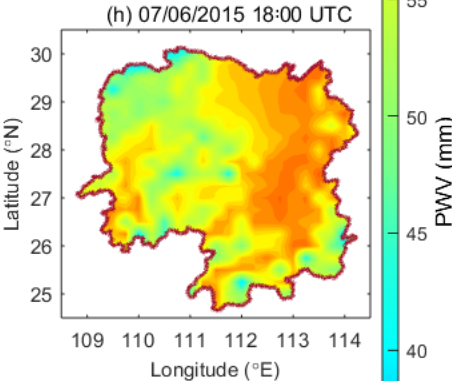

(I) $08 / 06 / 2015$ 18:00 UTC

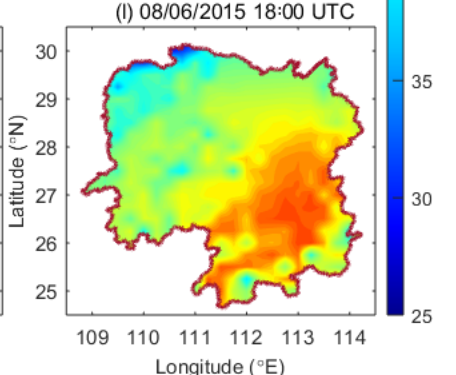

Longitude $\left({ }^{\circ} \mathrm{E}\right)$

Figure 9. Evolution of GNSS-derived PWV maps for the Hunan Province every 6 h from 00:00 UTC, 6 June 2015, to 18:00 UTC, 8 June 2015.

PWV from south to north, indicating that a large amount of moisture from the south flowed into Hunan. This is consistent with the precipitation pattern displayed in Fig. $8 \mathrm{a}$ in that the rainfall gradually decreased from south to north. On 7 June, significant PWV changes mainly concentrated in regions north of $28^{\circ} \mathrm{N}$. Especially in the northeast, PWV expe- rienced an increase of $10-15 \mathrm{~mm}$ from 00:00 to 12:00 UTC of 7 June and then dissipated quickly. On 8 June, obvious PWV decreases were observed in the northwest, whereas the southeast experienced a slight increase in PWV. The precipitation maps shown in Fig. $8 \mathrm{~b}$ and $\mathrm{c}$ also agree well with the PWV variations. From 7 to 8 June, the precipitation areas 

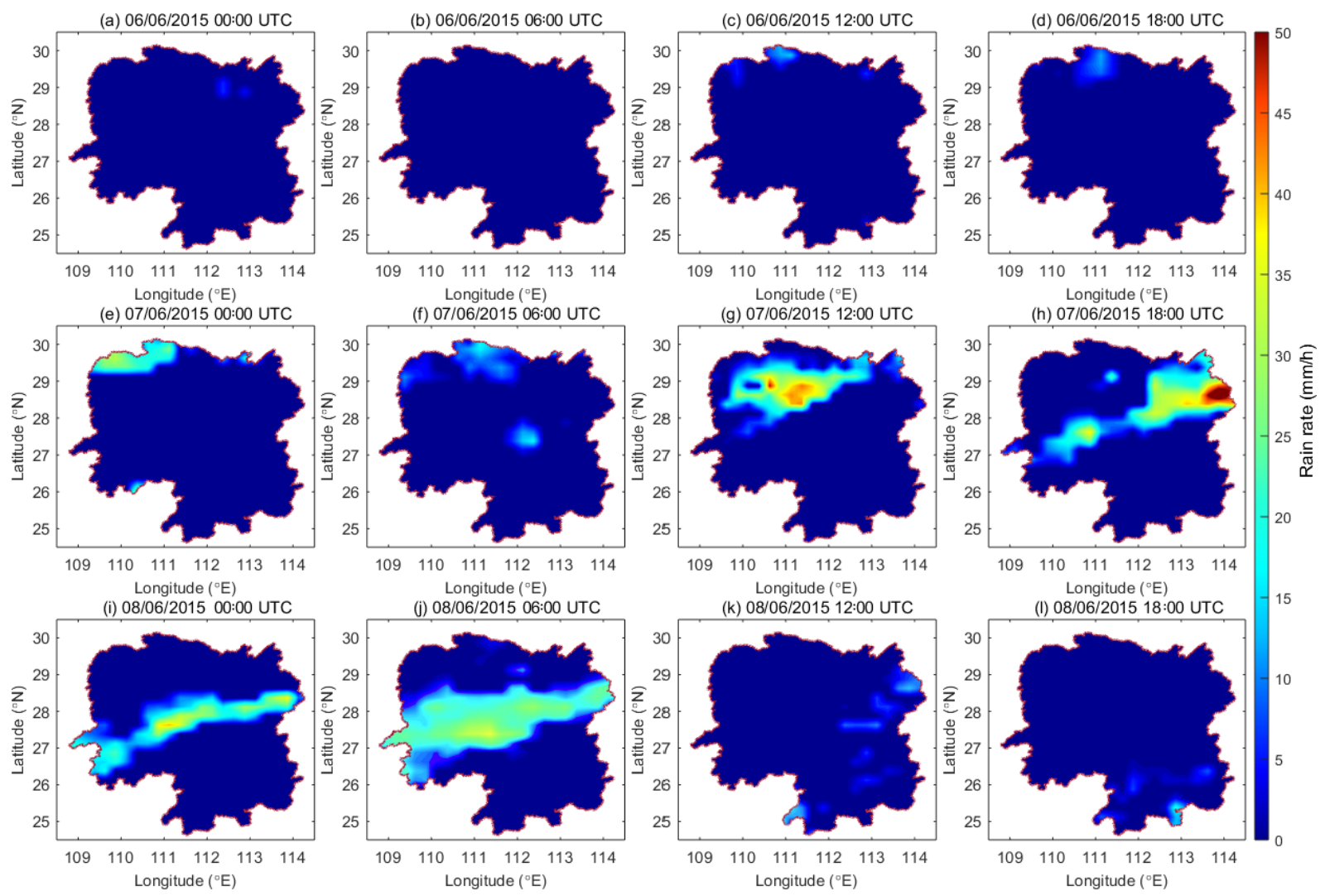

Figure 10. Evolution of rain rate maps for the Hunan Province every $6 \mathrm{~h}$ from 00:00 UTC, 6 June 2015, to 18:00 UTC, 8 June 2015. The rain rate data were retrieved from the TRMM with a spatial resolution of $0.25^{\circ} \times 0.25^{\circ}$.

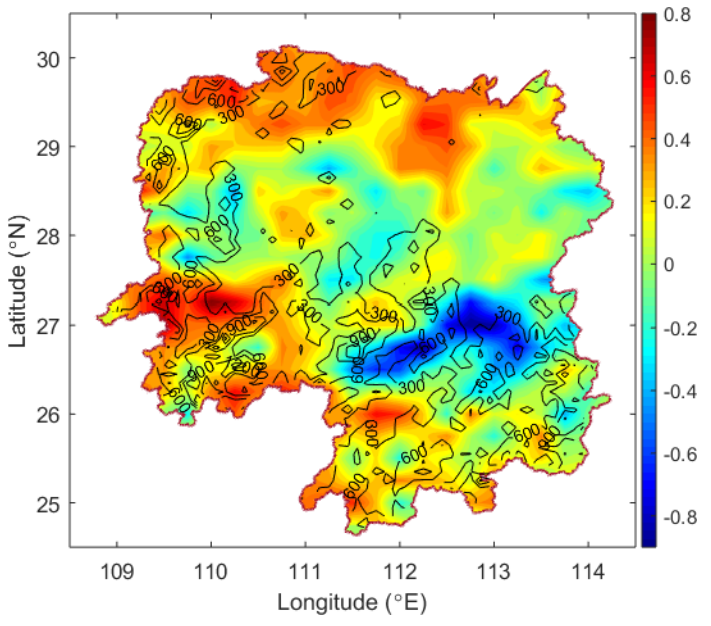

Figure 11. Map of the correlation coefficient between precipitation and PWV for the heavy rainfall process of 6-8 June 2015 over the Hunan Province. Black contours represent the elevation (unit: $\mathrm{m}$ ). The correlation coefficients were calculated for the accumulated precipitation and PWV for the 6-8 June 2015 period. largely decreased in the north whilst they slightly expanded in the south. Referring to the rain rates at the corresponding epochs, as shown in Fig. 10, we cannot observe close correlations between the PWV and the rain rate. Larger moisture convergence is not necessarily linked with higher rain rate occurrence. This is because the moisture convergence is not the only cause of precipitation, whilst it is also controlled by many other factors such as wind, temperature and terrain. However, the GNSS-derived PWV maps are able to reveal the moisture advection, transportation and convergence during the heavy-precipitation event.

In addition, Fig. 11 further exhibits the geographic distribution of the correlation coefficient between precipitation and PWV. The correlation coefficients vary greatly from -0.9 to 0.8 depending upon the location. High positive correlation coefficients are present in western regions between 27 and $27.5^{\circ} \mathrm{N}$. Precipitation and PWV show a high negative relationship in eastern regions between 26 and $27^{\circ} \mathrm{N}$. It can be observed from Figs. 1 and 11 that high positive or negative correlation coefficients mainly occur in mountainous regions, especially in hillsides and valleys. This is because the mesoscale orography creates favorable conditions for precipitation formation by generating moisture convergence and the small-scale orography plays an important role 
by triggering convective initiation and enhancement (Labbouz et al., 2013). Therefore, precipitation and PWV correlate more closely in mountainous regions than flat terrains, and mountainous regions are often sensitive areas prone to high frequency of heavy precipitation.

\section{Summary and conclusions}

The lack of collocated meteorological data at the GNSS station makes it difficult to take full advantage of GNSS observations for weather studies. This paper investigates an alternative method for accurate determination of PWV for nearreal-time applications using GNSS data and nearby synoptic observations. Moreover, we present a method to construct PWV maps with the use of a GNSS network, which is critical for improving the forecasting capability of extreme weathers, e.g., heavy rainfall.

The proposed approach for PWV map construction consists of two main steps: (1) the $P_{\mathrm{s}}$ and $T_{\mathrm{m}}$ derived at the nearby synoptic sites are interpolated onto the location of the GNSS stations through both vertical and horizontal adjustments and (2) vertical reduction and horizontal interpolation are performed to construct PWV map using the retrieved GNSS PWV. In this study, ERA-I data over the whole year of 2014 were employed to estimate all the parameters involved in the above two steps. The accuracies of the synopticinterpolated and GPT2w-derived $P_{\mathrm{s}}$ and $T_{\mathrm{m}}$ have been evaluated by comparing them against the observed values at three radiosonde sites in 2015. The RMSEs of $P_{\mathrm{s}}$ and $T_{\mathrm{m}}$ derived from the GPT $2 \mathrm{w}$ model vary in the range of $4.7-5.6 \mathrm{hPa}$ and $3.8-4.2 \mathrm{~K}$, respectively. The RMSEs from synoptic interpolation are $1.7-3.0 \mathrm{hPa}$ and $2.5-3.0 \mathrm{~K}$, respectively, which are much better than the GPT2w model.

In addition, GNSS-interpolated PWVs are assessed with respect to reference PWV values from radiosonde and ERAI. GNSS-interpolated PWVs show a good agreement with the radiosonde-measured ones with RMSEs varying in the range of $2.4-3.0 \mathrm{~mm}$. In the comparison with ERA-I, the biases of their differences vary from -8 to $6 \mathrm{~mm}$ over the Hunan Province and mountainous regions have a larger bias than flat regions in general. The RMSEs are within the range of 2-8 $\mathrm{mm}$, with those for most regions being less than $3 \mathrm{~mm}$. For PWV values less than $10 \mathrm{~mm}$ or more than $60 \mathrm{~mm}$, there is an obvious wet or dry bias relative to ERA-I. Furthermore, the RMSEs are found to increase with increased elevation in general, and a high correlation coefficient of 0.73 is obtained between RMSE and elevation.

We further apply the constructed PWV maps to monitor the water vapor variability during a large-scale heavyprecipitation event that occurred during 6-8 June 2015 in the Hunan Province. Results demonstrate that it is possible to reveal the moisture advection, transportation and convergence during the heavy rainfall using PWV maps. Since the orography provides favorable conditions for precipitation forma- tion, we also find that the precipitation and PWV correlate more closely in mountainous regions, especially in hillsides and valleys.

This research demonstrates the potentials of retrieving accurate PWV from GNSS observations using adjacent synoptic data and generating high-quality PWV maps from the GNSS network for weather prediction in near-real time. Future work will focus on the three following issues: (1) examining the reliability of the PWV map construction in other areas with highly dynamic water vapor, (2) assessing the performance of the constructed PWV maps with higher spatial and temporal resolutions, and (3) assimilating the PWV maps into a numerical prediction model to enhance the capability of extreme weather forecasting.

Data availability. The ECMWF ERA-Interim reanalysis products are available online (http://apps.ecmwf.int/datasets/) (ECMWF, 2018). The radiosonde data were obtained from http://weather. uwyo.edu/upperair/sounding.html (University of Wyoming, 2018). The TRMM rainfall data were provided by https://pmm.nasa. gov/data-access/downloads/trmm (NASA, 2018). The synoptic observations were provided by http://rda.ucar.edu/datasets/ds336.0/ (NCAR, 2018). The SRTM30 PLUS data were provided by http: //topex.ucsd.edu/index.html (University of California San Diego, 2018). The GNSS observations of the Hunan GNSS network presented in this study are available from the authors upon request (yeary124@csu.edu.cn).

Author contributions. BC and WD designed this study, developed the methodology, performed the analysis and wrote the manuscript. ZL, LW, CK and MAO provided guidance and helped polish the manuscript.

Competing interests. The authors declare that they have no conflict of interest.

Special issue statement. This article is part of the special issue "Advanced Global Navigation Satellite Systems tropospheric products for monitoring severe weather events and climate (GNSS4SWEC) (AMT/ACP/ANGEO inter-journal SI)". It is not associated with a conference.

Acknowledgements. This work was supported by the Research Grant for Specially Hired Associate Professor of Central South University (project no. 202045005). Zhizhao Liu thanks the Hong Kong Polytechnic University (projects 152149/16E, 152103/14E, $152168 / 15 \mathrm{E}$ and 1-BBYH) and the grant supports from the Key Program of the National Natural Science Foundation of China (project no. 41730109). The European Centre for Medium-Range Weather Forecasts is appreciated for providing the ECMWF reanalysis data. The TRMM rainfall data were provided by the National Aeronautics and Space Administration (NASA), via 
https://pmm.nasa.gov/data-access/downloads/trmm (last access: March 2018). The synoptic observations were provided by the National Center for Atmospheric Research (NCAR), from the website http://rda.ucar.edu/datasets/ds336.0/ (last access: March 2018). The SRTM30 PLUS data were provided by the Satellite Geodesy research group at the Institute of Geophysics and Planetary Physics, Scripps Institution of Oceanography, University of California San Diego, from the website http://topex.ucsd.edu/index.html (last access: March 2018). Finally, the authors want to thank the University of Wyoming for providing the radiosonde data.

Edited by: Roeland Van Malderen

Reviewed by: three anonymous referees

\section{References}

Ahrens, C. and Samson, P.: Extreme weather and climate, 1 Edn., 22 February 2010, Brooks Cole, United States of America, 2011. Alshawaf, F., Fuhrmann, T., Knopfler, A., Luo, X., Mayer, M., Hinz, S., and Heck, B.: Accurate Estimation of Atmospheric Water Vapor Using GNSS Observations and Surface Meteorological Data, IEEE Trans. Geosci. Remote Sens., 53, 3764-3771, https://doi.org/10.1109/TGRS.2014.2382713, 2015.

Alshawaf, F., Balidakis, K., Dick, G., Heise, S., and Wickert, J.: Estimating trends in atmospheric water vapor and temperature time series over Germany, Atmos. Meas. Tech., 10, 3117-3132, https://doi.org/10.5194/amt-10-3117-2017, 2017.

Askne, J. and Nordius, H.: Estimation of tropospheric delay for microwaves from surface weather data, Radio Sci., 22, 379-386, 1987.

Becker, J. J., Sandwell, D. T., Smith, W. H. F., Braud, J., Binder, B., Depner, J., Fabre, D., Factor, J., Ingalls, S., Kim, S.H., Ladner, R., Marks, K., Nelson, S., Pharaoh, A., Trimmer, R., Von Rosenberg, J., Wallace, G., and Weatherall, P.: Global Bathymetry and Elevation Data at 30 Arc Seconds Resolution: SRTM30_PLUS, Mar. Geod., 32, 355-371, https://doi.org/10.1080/01490410903297766, 2009.

Bevis, M., Businger, S., Herring, T. A., Rocken, C., Anthes, R. A., and Ware, R. H.: GPS meteorology: Remote sensing of atmospheric water vapor using the Global Positioning System, J. Geophys. Res.-Atmos., 1984-2012, 97, 15787-15801, 1992.

Bevis, M., Businger, S., Chiswell, S., Herring, T., Anthes, R., Rocken, C., and Ware, R. H.: GPS Meteorology: Mapping zenith wet delays onto precipitable water, J. Appl. Meteorol., 33, 379386, 1994

Bock, O., Keil, C., Richard, E., Flamant, C., and Bouin, M.: Validation of precipitable water from ECMWF model analyses with GPS and radiosonde data during the MAP SOP, Q. J. R. Meteorol. Soc., 131, 3013-3036, https://doi.org/10.1256/qj.05.27, 2005

Boehm, J., Niell, A., Tregoning, P., and Schuh, H.: Global Mapping Function (GMF): A new empirical mapping function based on numerical weather model data, Geophys. Res. Lett., 33, https://doi.org/10.1029/2005GL025546, 2006.

Boehm, J., Heinkelmann, R., and Schuh, H.: Short Note: A global model of pressure and temperature for geodetic applications, J. Geod., 81, 679-683, https://doi.org/10.1007/s00190-007-01353,2007 .
Boehm, J., Möller, G., Schindelegger, M., Pain, G., and Weber, R.: Development of an improved empirical model for slant delays in the troposphere (GPT2w), GPS Solut., 19, 433-441, https://doi.org/10.1007/s10291-014-0403-7, 2015.

Brenot, H., Neméghaire, J., Delobbe, L., Clerbaux, N., De Meutter, P., Deckmyn, A., Delcloo, A., Frappez, L., and Van Roozendael, M.: Preliminary signs of the initiation of deep convection by GNSS, Atmos. Chem. Phys., 13, 5425-5449, https://doi.org/10.5194/acp-13-5425-2013, 2013.

Chen, B. and Liu, Z.: A Comprehensive Evaluation and Analysis of the Performance of Multiple Tropospheric Models in China Region, IEEE Trans. Geosci. Remote Sens., 54, 663-678, https://doi.org/10.1109/TGRS.2015.2456099, 2016a.

Chen, B. and Liu, Z.: Global Water Vapor Variability and Trend from the Latest 36-Year (1979 to 2014) Data of ECMWF and NCEP Reanalyses, Radiosonde, GPS and Microwave Satellite, J. Geophys. Res.-Atmos., 121, 11442-11462, https://doi.org/10.1002/2016JD024917, 2016b.

Dach, R., Lutz, S., Walser, P., and Fridez, P.: Bernese GNSS Software Version 5.2, https://doi.org/10.7892/boris.72297, 2015.

Davis, J. L., Herring, T. A., Shapiro, I. I., Rogers, A. E. E., and Elgered, G.: Geodesy by radio interferometry: Effects of atmospheric modeling errors on estimates of baseline length, Radio Sci., 20, 1593-1607, 1985.

Dee, D. P., Uppala, S. M., Simmons, A. J., Berrisford, P., Poli, P., Kobayashi, S., Andrae, U., Balmaseda, M. A., Balsamo, G., Bauer, P., Bechtold, P., Beljaars, A. C. M., van de Berg, L., Bidlot, J., Bormann, N., Delsol, C., Dragani, R., Fuentes, M., Geer, A. J., Haimberger, L., Healy, S. B., Hersbach, H., Hólm, E. V., Isaksen, L., Kållberg, P., Köhler, M., Matricardi, M., McNally, A. P., Monge-Sanz, B. M., Morcrette, J.-J., Park, B.-K., Peubey, C., de Rosnay, P., Tavolato, C., Thépaut, J.-N., and Vitart, F.: The ERA-Interim reanalysis: configuration and performance of the data assimilation system, Q. J. Roy. Meteorol. Soc., 137, 553597, https://doi.org/10.1002/qj.828, 2011.

Dousa, J. and Elias, M.: An improved model for calculating tropospheric wet delay, Geophys. Res. Lett., 41, 4389-4397, https://doi.org/10.1002/2014GL060271, 2014.

Durre, I., Vose, R. S., and Wuertz, D. B.: Overview of the integrated global radiosonde archive, J. Climate, 19, 53-68, 2006.

ECMWF: European Centre for Medium-Range Weather Forecasts (ECMWF) ERA-Interim reanalysis, available at: http://apps. ecmwf.int/datasets, last access: March 2018.

Guerova, G., Jones, J., Douša, J., Dick, G., de Haan, S., Pottiaux, E., Bock, O., Pacione, R., Elgered, G., Vedel, H., and Bender, M.: Review of the state of the art and future prospects of the groundbased GNSS meteorology in Europe, Atmos. Meas. Tech., 9, 5385-5406, https://doi.org/10.5194/amt-9-5385-2016, 2016.

Kummerow, C., Barnes, W., Kozu, T., Shiue, J., and Simpson, J.: The tropical rainfall measuring mission (TRMM) sensor package, J. Atmos. Ocean. Tech., 15, 809-817, 1998.

Labbouz, L., Van Baelen, J., Tridon, F., Reverdy, M., Hagen, M., Bender, M., Dick, G., Gorgas, T., and Planche, C.: Precipitation on the lee side of the Vosges Mountains: Multi-instrumental study of one case from the COPS campaign, Meteorol. Z., 22, 413-432, https://doi.org/10.1127/0941-2948/2013/0413, 2013.

Lagler, K., Schindelegger, M., Boehm, J., Krásná, H., and Nilsson, T.: GPT2: Empirical slant delay model for radio space 
geodetic techniques, Geophys. Res. Lett., 40, 1069-1073, https://doi.org/10.1002/grl.50288, 2013.

Lau, K.-M. and Wu, H.-T.: Climatology and changes in tropical oceanic rainfall characteristics inferred from Tropical Rainfall Measuring Mission (TRMM) data (1998-2009), J. Geophys. Res., 116, https://doi.org/10.1029/2011JD015827, 2011.

Li, L., Wu, S., Wang, X., Tian, Y., He, C. and Zhang, K.: Seasonal Multifactor Modelling of Weighted-Mean Temperature for Ground-Based GNSS Meteorology in Hunan, China, Adv. Meteorol., 1-13, https://doi.org/10.1155/2017/3782687, 2017.

Li, L., Wu, S.-Q., Wang, X.-M., Tian, Y., He, C.-Y. and Zhang, K.F.: Modelling of weighted-mean temperature using regional radiosonde observations in Hunan China, Terr. Atmos. Ocean. Sci., 29, 187-199, https://doi.org/10.3319/TAO.2017.05.26.01, 2018.

Lu, C., Li, X., Li, Z., Heinkelmann, R., Nilsson, T., Dick, G., Ge, M., and Schuh, H.: GNSS tropospheric gradients with high temporal resolution and their effect on precise positioning, J. Geophys. Res.-Atmos.,, 121, 912-930, https://doi.org/10.1002/2015JD024255, 2016.

Lu, N., Qin, J., Gao, Y., Yang, K., Trenberth, K. E., Gehne, M., and Zhu, Y.: Trends and variability in atmospheric precipitable water over the Tibetan Plateau for 2000-2010, Int. J. Climatol., 35, 1394-1404, https://doi.org/10.1002/joc.4064, 2015.

Mohanakumar, K.: Stratosphere troposphere interactions: An introduction, Springer, New York, USA, 2008.

Moradi, I., Soden, B., Ferraro, R., Arkin, P., and Vömel, H.: Assessing the quality of humidity measurements from global operational radiosonde sensors, J. Geophys. Res.-Atmos., 118, 80408053, https://doi.org/10.1002/jgrd.50589, 2013.

Musa, T. A., Amir, S., Othman, R., Ses, S., Omar, K., Abdullah, K., Lim, S. and Rizos, C.: GPS meteorology in a low-latitude region: Remote sensing of atmospheric water vapor over the Malaysian Peninsula, J. Atmos. Sol.-Terr. Phys., 73, 2410-2422, https://doi.org/10.1016/j.jastp.2011.08.014, 2011.

NASA: National Aeronautics and Space Administration (NASA) TRMM precipitation data, available at: https://pmm.nasa.gov/ data-access/downloads/trmm, last access: March 2018.

Nash, J., Oakley, T., Vömel, H., and Li, W.: WMO Intercomparison of high quality radiosonde systens, World Meteorological Organization, Instruments and observations, Yangjiang, China, 2011.

NCAR: National Center for Atmospheric Research (NCAR) synoptic data, available at: http://rda.ucar.edu/datasets/ds336.0/T, last access: March 2018.

Pacione, R., Araszkiewicz, A., Brockmann, E., and Dousa, J.: EPN-Repro2: A reference GNSS tropospheric data set over Europe, Atmos. Meas. Tech., 10, 1689-1705, https://doi.org/10.5194/amt-10-1689-2017, 2017.
Rüeger, J. M.: Refractive index formulae for radio waves, in Integration of Techniques and Corrections to Achieve Accurate Engineerin, p. 13, Washington, D.C. USA., 2002.

Saastamoinen, J.: Atmospheric correction for the troposphere and stratosphere in radio ranging of satellites, Geophys. Monogr. Ser., 15, 247-251, 1972.

University of Wyoming: Radiosonde data, Department of Atmospheric Science of the University of Wyoming, http://weather. uwyo.edu/upperair/sounding.html, last access: March 2018.

Van Baelen, J., Reverdy, M., Tridon, F., Labbouz, L., Dick, G., Bender, M., and Hagen, M.: On the relationship between water vapour field evolution and the life cycle of precipitation systems, Q. J. Roy. Meteorol. Soc., 137, 204-223, https://doi.org/10.1002/qj.785, 2011.

Wang, J., Zhang, L., Dai, A., Van Hove, T., and Van Baelen, J.: A near-global, 2-hourly data set of atmospheric precipitable water from ground-based GPS measurements, J. Geophys. Res., 112, D11107, https://doi.org/10.1029/2006JD007529, 2007.

Wang, X., Zhang, K., Wu, S., He, C., Cheng, Y., and Li, X.: Determination of zenith hydrostatic delay and its impact on GNSSderived integrated water vapor, Atmos. Meas. Tech., 10, 28072820, https://doi.org/10.5194/amt-10-2807-2017, 2017.

Yao, Y., Shan, L., and Zhao, Q.: Establishing a method of shortterm rainfall forecasting based on GNSS-derived PWV and its application, Sci. Rep., 7, 12465, https://doi.org/10.1038/s41598017-12593-z, 2017.

Yao, Y. B., Zhang, B., Yue, S. Q., Xu, C. Q., and Peng, W. F.: Global empirical model for mapping zenith wet delays onto precipitable water, J. Geod., 87, 439-448, https://doi.org/10.1007/s00190013-0617-4, 2013.

Yuan, Y., Zhang, K., Rohm, W., Choy, S., Norman, R., and Wang, C.-S.: Real-time retrieval of precipitable water vapor from GPS precise point positioning, J. Geophys. Res.-Atmos., 119, 10044 10057, https://doi.org/10.1002/2014JD021486, 2014.

Zhang, H., Yuan, Y., Li, W., Ou, J., Li, Y., and Zhang, B.: GPS PPP-derived precipitable water vapor retrieval based on $\mathrm{Tm} / \mathrm{Ps}$ from multiple sources of meteorological data sets in China, J. Geophys. Res.-Atmos., 122, 4165-4183, https://doi.org/10.1002/2016JD026000, 2017.

Zhang, K., Manning, T., Wu, S., Rohm, W., Silcock, D., and Choy, S.: Capturing the signature of severe weather events in Australia using GPS measurements, IEEE J. Sel. Top. Appl. Earth Obs. Remote Sens., 8, 1839-1847, https://doi.org/10.1109/JSTARS.2015.2406313, 2015. 